\title{
Fernando Pessoa e Jacques Lacan: constelações, letra e livro
}

\author{
Márcia Maria Rosa Vieira
}

Resumo

\begin{abstract}
Este artigo colocou lado a lado a poética do escritor Fernando Pessoa, principalmente no seu Livro do desassossego, e a teoria psicanalítica de Jacques Lacan, em especial aquela formulada nos anos 70, de modo a examinar o "funcionamento constelar" e o "livro" como modos de dar forma ao acaso, à contingência.
\end{abstract}

Palavras-chave: Constelações. Letra. Livro. Literatura. Psicanálise.

Se cada escritor cria os seus precursores (BORGES, 1999, p. 88-90), se cada época cria os seus antepassados, não parece de todo despropositado incluir o escritor português Fernando Pessoa entre os precursores da Literatura Comparada. Inegavelmente na poesia, e de algum modo na prosa, ele desenvolve um autêntico exercício de comparativismo. Para localizá-lo, basta uma olhadela no índice das Obras em Prosa, onde se lê "Alberto Caeiro visto por Álvaro de Campos", "Ricardo Reis em controvérsia com Álvaro de Campos", "Ricardo Reis visto por Fernando Pessoa", "Caeiro e Whitman", "Álvaro de Campos, influência de Caeiro", etc. (PESSOA, 1986, p. 725-726).

Que a obra de um escritor possa não apenas se prestar a, mas também ser um exercício comparatista, deve-se à dimensão de diversidade que ela traz em si. Nesse sentido, dizendo-se "o múltiplo que nunca teve uma só personalidade" e "sabendo-se o ponto de reunião de uma pequena humanidade só sua" (PESSOA, 1986, p. 45-46), Pessoa apresentou a sua produção literária como os resultados escritos de uma multiplicidade. Desse modo, ele recolocou o debate sobre o Um e o Múltiplo, presente desde os pré-socráticos, no contexto da modernidade. ${ }^{1}$ A reincidência desse debate sobre o tema do sujeito no mundo contemporâneo constituiu uma das razões da escolha da poética de Fernando Pessoa como tema da tese intitulada "Fernando Pessoa e Jacques Lacan: constelações, letra e livro".

A constatação inicial é a de que, morto como universal, o sujeito renasce "na multiplicidade de identidades novas - e não tão novas! - como resultado da dissolução dos lugares desde os quais os sujeitos universais falaram - explosão de identidades étnicas [...]" (LACLAU, 1996, p. 45-46). Na medida em que, desde os inícios da modernidade, a poética pessoana sinalizou a existência dessa problemática, ela não apenas constitui um operador de leitura dos novos tempos, bem como se presta, ela própria, a uma releitura. Nessa retomada, ela beneficia-se "da efervescência presente atualmente no campo da epistemologia interdisciplinar e da 
conseqüente liberação do Múltiplo como tratamento da natureza hipercomplexa do real" (MARQUES, 1999, p. 64).

No contexto interdisciplinar, não é difícil perceber que muito pouca coisa foi produzida até agora no sentido de uma aproximação entre Fernando Pessoa e Jacques Lacan, tanto no campo das Letras quanto no da psicanálise. Portanto, com vistas a ampliar esse campo de interlocução, pretendeu-se aproximar a poética do escritor português e a psicanálise lacaniana, principalmente aquela formulada nos anos 70 , na qual, finalizado o momento estruturalista, a teoria psicanalítica caminha no sentido de uma escritura não linear, dita borromeana. Esse movimento e a teoria da letra que ele traz encontram no texto "Lituraterra" (1971) e nos seminários Mais, ainda (19721973) e L'insu que sait de l'une bévue s'aile à mourre (1976-1977) formulações crucias, daí o interesse em tratá-los de perto.

\section{De "ocidentado" a "japonizado": um sujeito constelar}

Nos anos 70, Leyla Perrone-Moisés extraiu do texto de Lacan, "Lituraterra", a versão do "sujeito ocidentado" e mostrou que o acidente do Ocidente localiza-se na fratura entre o sujeito e o objeto, entre a ciência e a metafísica, entre o intelectualismo e o sentimentalismo, e que essa fratura atravessa toda a poética pessoana. Trata-se agora de apanhar a questão por uma outra ponta, a ponta do "sujeito japonizado, constelado". Nesse sentido, interessa recortar no "Lituraterra" os impasses que a pulverização do sujeito cria e as saídas que ela constrói: no caso da obra do escritor português, a ficção heterônima e a escritura do desassossego.

Se o contexto de uma época é percebido por um escritor através de seu temperamento (AIEX, 1985, p. 17), é inusitado aquilo que o temperamento pessoano (sempre tendendo para a despersonalização) fará com os traços que a modernidade herda do Romantismo alemão e do Simbolismo francês. Ao se contrapor ao preceito clássico "conheça-te!", Pessoa enuncia o preceito em jogo na modernidade, "desconheça-te!", e, para ele, "desconhecer-se conscienciosamente é o emprego ativo da ironia" (PESSOA, 2000, p. 165). Escravo da multiplicidade de si próprio, o modo irônico pelo qual ele se desconhece é a heteronímia, isto é, a criação de uma nebulosa de escritores e de suas respectivas ficções. Até o momento, pode-se afirmar que a galáxia pessoana chega a 72 heterônimos (LOPES, 1990, p. 167-168), criados, muitos deles, segundo um processo que não deixa de se aproximar do dispositivo do Witz, do dito espirituoso (Pessoa, 1986, p. 93 et seq).

Pela boca de um de seus Outros - Bernardo Soares - o escritor diz:

Cada qual tem o seu álcool. Tenho álcool bastante em existir. Bêbado de me sentir, vagueio e ando certo. Se são horas, recolho-me ao escritório como qualquer outro. Se não são horas, vou até ao rio fitar o rio, como qualquer outro. Sou igual. E por traz de isso, céu meu, constelo-me às escondidas e tenho o meu infinito ( $L$. do D., 20.07.1930, Fragmento 55).

Pessoa apresenta aí um modo de ser que ultrapassa a dimensão de uma ocorrência isolada. O dito funcionamento constelar emergiu e vigorou no final do século XIX e na primeira metade do século XX. Inaugurado por Stéphane Mallarmé, com o seu poema "Um lance de dados" (1897), esse acento constelar incidiu não apenas sobre o espaço poético, mas também sobre o campo do pensamento, no qual ele criou um estilo mosaico, tal como em Walter Benjamin. Ele manifestou-se ainda no campo das artes plásticas, como é o caso do pintor catalão Joan Miró, entre outros. No 
entanto, além de constatar a emergência do constelar no horizonte das artes e, em especial, das artes literárias, é interessante observar a sua incidência sobre o sujeito, seja ele o sujeito poético ou psicanalítico. Isso leva a um outro discurso e a uma outra concepção de sujeito, presentes no horizonte da modernidade: a psicanálise de Sigmund Freud. Poder-se-ia dizer que, para ambos, trata-se de uma subjetividade constelar? Se tivessem se encontrado, como teria sido a conversa entre Pessoa e o Freud do sonho "A injeção feita em Irma"?

Pelo que tudo indica, embora o psicanalista de Viena nos aproxime desse sujeito "desconhecido de si mesmo" (PAZ, 1996, p. 201), algo daquilo que a perspectiva constelar esboça se perde, a saber, a passagem da linearidade à espacialidade. Para localizá-la e extrair-lhe as conseqüências - o que pressupõe uma distinção bem estabelecida entre as noções de significante e de letra - é necessário chegar às formulações de Lacan, nas quais o termo constelação aparece diversas vezes. Entre outras, destaca-se aquela na qual ele menciona a "constelação de insígnias" (Lacan, 1958/1998, p. 686), constelação de traços significantes, de marcas, de emblemas que apresentam o sujeito, nomeando-o. É nesse último sentido que o termo ressurge em "Lituraterra" (1971), texto no qual o psicanalista interroga se o constelar não levaria a uma mudança no estatuto do sujeito.

A partir do seu encontro com as particularidades da língua japonesa, Lacan indica que, nela, o campo das identificações sofre uma pulverização, e que isso dá ao sujeito japonês um estatuto constelar. Para fazer frente a essa pulverização, esse sujeito se desdobra, de tal modo que um dos seus registros "se satisfaz" pela referência à escritura, e o outro, pela referência à palavra. Diante dessas considerações, pode-se hipostasiar que o sujeito da poética pessoana é um sujeito japonês, e, isso, à medida que ele oscila entre os seus cerimoniais de composição e decomposição no jogo heterônimo (exercício de ficção, de literatura) e o privilégio da letra (prática de fixão, lituraterra), jogo escritural, portanto. Nesse sentido, a escritura do desassossego apresenta um outro modo de satisfação em relação àquele em jogo na ficção heterônima.

A aproximação entre o campo pulsional e a letra, sugerida pela língua japonesa, Lacan a retoma logo depois, quando, servindo-se da matemática calcada na teoria dos conjuntos, matemática bourbakista, introduz a noção de enxame. Novos operadores surgem e, com eles, a proposta de uma escritura e uma leitura "fragmentária, não dedutiva e localizada". A partir daí, a teoria da letra construída no último momento do ensino de Lacan desemboca no campo do poema, ou melhor, da poética. Jakobson entra novamente no horizonte. Com o retorno à poética, ganha forma a questão de um poético pulsional no qual o inconsciente faz as suas elucubrações de saber sobre a alíngua (lalangue), bem como as suas equivocações entre o som e o sentido. Em todos esses três momentos - japonês, matemático e poemático - a letra articula-se ao campo do gozo e, apesar de dizer das unaridades, ela multiplica-se.

A noção de letra apresenta-se, portanto, inserida em um campo de ressonâncias no qual se encontram as pulsões, cujas aventuras Sigmund Freud indagou sob o termo triebschicksale. Em Lacan, a caligrafia, a matemática e o poema surgem como modalidades de exercício da letra que nos levam a uma questão fundamental: seriam essas versões da letra operadores de leitura precisos e sutis o bastante para o trato do texto literário e, mais especificamente, para a leitura da poética do escritor português, Fernando Pessoa?

Com essas últimas elaborações de Lacan, os heterônimos pessoanos são legíveis como uma constelação de insígnias, isto é, como signos de gozo e, nesse viés, levam a 
um questionamento da lógica simbólica e de seu enlaçamento em cadeias significantes, seriadas de modo linear pela lingüística saussuriana. Em vista disso, as Constelações constituem a espinha dorsal do percurso. No entanto, além de constatar o modo de funcionamento constelar presente na poética pessoana, observa-se que, se, no fugaz momento da constelação, o poético encontra uma disciplina que dá forma ao acaso (CAMPOS, 1975, p. 95), um outro modo poético de tratamento da contingência (mais duradouro, sem dúvida) surge sob a forma do Livro. Trazido por Mallarmé como um fantasma poético, como uma tentativa de cernir de modo conclusivo o universo do discurso, com Fernando Pessoa o Livro torna-se um "definitivo de refugos" e funciona preferencialmente como um sintoma, um parceiro-sintoma.

Construído na forma de fragmentos, o Livro do desassossego, escrito pelo semiheterônimo Bernardo Soares, desloca o acento constelar do campo da subjetividade, fazendo-o incidir sobre o texto, que ganha um estilo mosaico. Com isso, ele abre a discussão sobre o ato da leitura: de que modo ler um livro de fragmentos? Do início ao fim, reconstituindo uma linearidade? De modo retroativo, invertendo a flecha do tempo? Colocando fragmentos uns ao lado dos outros, de modo a produzir um choque e iluminar algo novo? De modo oblíquo, traçando pontos de convergência e/ou divergência entre temas escolhidos? Ao acaso, abrindo aleatoriamente as páginas?

\section{O debate sobre o Um e o Múltiplo}

Que a pessoana seja uma poética do Múltiplo não nos poupa de recolocar em questão o campo do Um. Por conseguinte, interessa trabalhar com a hipótese de que o Um pode ser tomado como um operador lógico, ou mesmo como um operador de leitura que abre a possibilidade de localizar, a cada vez, o elemento que amarra o conjunto, de modo que ele não se perca em uma simples dispersão. Ao delinear a sua como uma Poética do Múltiplo, Pessoa não evitou provocar o Um, inquietá-lo; deixouo, portanto, no horizonte. Um século depois, não seria interessante, vez por outra, desassossegar o Múltiplo? Onde, pois, localizar o Um na literatura de Pessoa? Ao seguirmos nessa direção, deparamos, tal como mencionado anteriormente, com dois modos preferenciais através dos quais essa poética dá forma ao informe, ou seja, racionaliza a contingência: as "constelações" e o "livro".

Para finalizar, é importante observar ainda que seria possível e interessante indagar sobre a incidência dessas elaborações sobre o trabalho clínico da psicanálise: de que modo o funcionamento constelar, tão marcante na poética pessoana, aproximar-se-ia disso que a teoria lacaniana formulou com a pluralização dos Nomes do Pai? Para a psicanálise, o binarismo traz, fundamentalmente, a questão do simbólico e de seus limites; em outros termos, está em jogo aí o pai -tomado como uma metáfora - em sua função de regulação do campo do gozo. Que a lógica de leitura e de funcionamento do mundo e do sujeito contemporâneos seja estabelecida por "transbordamentos", ${ }^{2}$ e não mais por metáforas, como nos propõe Roland Barthes, não deixa de comportar uma interrogação sobre a (in)existência do Outro paterno como instância reguladora. Nesse viés, para a psicanálise trata-se "não mais simplesmente de uma clínica ordenada pelo eixo simbólico sustentado no Nome do Pai, clínica da necessidade fálica, mas de uma clínica do impossível e da contingência, resultante da pluralidade dos Nomes" (BROUSSE, 1998, p. 66).

É interessante anotar ainda um outro modo pelo qual a psicanálise contemporânea participa do debate sobre o Um e o Múltiplo. Já se propôs que, ao 
invés de se falar United States, e se fale United Symptoms, Sintomas Unidos, ou seja, o sintoma seria entendido como um modo específico de gozo e surgiria como algo que une os sujeitos na contemporaneidade. Por conseguinte, como contrapartida ao Universal, ter-se-ia "um universo povoado de deuses e de gozos locais" (MILLER; LAURENT, 1998, p. 16-17), ou, nos termos de Lacan, um universo povoado pelos "descaminhos de nosso gozo" (LACAN, 1993, p. 58).

Estaríamos assim tão longe de Moisés e de seu monoteísmo?

\footnotetext{
Notas

1

${ }^{1}$ Essa problemática aparece nas discussões contemporâneas dos Estudos Literários com os termos: universal e particular, global e local, entre outros.

2 "[...] não se trata mais de reencontrar, na leitura do mundo e do sujeito, simples oposições, mas transbordamentos, superposições, escapes, deslizamentos, deslocamentos, derrapagens". (BARTHES, Roland. Roland Barthes por Roland Barthes. São Paulo: Cultrix. 1977. p.77)
}

Abstract

This papers placed the poetic of the writer Fernando Pessoa, specially in his Book of disquiet, side by side with the psychoanalytic theory formulated by Jacques Lacan, mainly in the seventies, in order to examinate the "constellations" and the "book" as ways of giving shape and handling the contingence.

Key words: Constellations. Letter. Book, Literature. Psychoanalysis.

Referências

AIEX, Anoar. O Livro do desassossego e a crise do pensamento europeu. In: ACTAS do II Congresso Internacional de Estudos Pessoanos. Porto: Centro de Estudos Pessoanos, 1985.

BERARDINELLI, Cleonice. Estudo introdutório. In: PESSOA, Fernando. Obras em prosa. Organização, introdução e notas de Cleonice Berardinelli. Rio de Janeiro: Nova Aguilar, 1986. v. único.

BORGES, Jorge Luis. Kafka e seus precursores. In: BORGES, Jorge Luís. Obras completas. São Paulo: Globo, 1999. v.2.

BROUSSE, Marie-Hélène. Les noms, le père, le symptôme. La cause freudienne: revue de Psychanalyse. Les Maladies du nom propre. Paris: Navarin; Seuil, 1998.

CHARTIER, Roger. A ordem dos livros: leitores, autores e bibliotecas na Europa entre os séculos XIV e XVIII. Brasília: Universidade de Brasília, 1999.

FREGE, Johann Gottlob. Que é uma função? In: FREGE, Johann Gottlob. Lógica e filosofia da linguagem. São Paulo: Cultrix, 1978. 
LACAN, Jacques. Informe sobre o relatório de Daniel Lagache.

LACAN, Jacques. Escritos. Rio de Janeiro: JZE, 1998.

LACAN, Jacques. Televisão. Rio de Janeiro: JZE, 1993.

LACLAU, Ernest. Emancipación y diferencia. Argentina: Ariel, 1996.

LOPES, Teresa Rita. Pessoa por conhecer: roteiro para uma expedição. Lisboa: Editorial Estampa, 1990. v.1.

MARQUES, Reinaldo. Literatura comparada e estudos culturais: diálogos interdisciplinares. In: CARVALHAL, Tânia (Org.). Culturas, contextos e discursos: limiares críticos no comparativismo. Porto Alegre: Editora da UFRGS, 1999.

MILLER, Jacques-Alain; LAURENT, Éric. O Outro que não existe e seus comitês de ética. Curinga, Revista da Escola Brasileira de Psicanálise - MG, Belo Horizonte, v.12, p. 16-17, set. 1998.

PAZ, Octavio. O desconhecido de si mesmo: Fernando Pessoa. In: PAZ, Octavio. Signos em rotação. 3.ed. São Paulo: Perspectiva, 1996.

PESSOA, Fernando. Obras em prosa. Organização, introdução e notas de Cleonice Berardinelli. Rio de Janeiro: Nova Aguilar, 1986. v. único.

PESSOA, Fernando. Carta a Adolfo Casais Monteiro (13.01.1935). In: PESSOA, Fernando. Obras em prosa. Organização, introdução e notas de Cleonice Berardinelli. Rio de Janeiro: Nova Aguilar, 1986. v. único.

PESSOA, Fernando. Fragmento 149. In: PESSOA, Fernando. O livro do desassossego composto por Bernardo Soares, ajudante de Guarda-Livros na cidade de Lisboa. Organização Richard Zenith. São Paulo: Companhia das Letras, 2000.

PIGNATARI, Augusto; CAMPOS, Décio; CAMPOS, Haroldo. Teoria da poesia concreta: textos críticos e manifestos 1950-1960. São Paulo: Livraria Duas Cidades, 1975. 